\title{
Comercio, instituciones y orden espontáneo durante la plena Edad Media en el Occidente Medieval
}

\author{
Trade, institutions and spontaneous order during \\ the high Middle Ages in the medieval West \\ ROQUE SAMPEDRO LÓPEZ \\ Universidad de Santiago de Compostela \\ roque.sampedro@rai.usc.es \\ https://orcid.org/0000-0001-8369-9635 \\ http://dx.doi.org/10.15304/sm.31.5952
}

\section{RESUMEN}

Este artículo busca aproximarse al comercio de la plena Edad Media en el Occidente Medieval a través del concepto de orden espontáneo. Para ello, se explicará, en primer lugar, la noción de orden espontáneo, así como otros conceptos relacionados, como el de institución o el de comercio. En segundo lugar, se estudiarán algunas de las instituciones que hacen posible el comercio plenomedieval, como los señoríos o los movimientos de la paz y tregua de Dios. Finalmente, en tercer lugar, se analizará el comercio medieval como un orden espontáneo, formado por fenómenos como los mercados y las ferias, los contratos mercantiles, o las organizaciones de los mercaderes.

Palabras clave: comercio medieval, orden espontáneo, señoríos, paz y tregua de Dios.

\begin{abstract}
This article seeks to approach the trade of the high Middle Ages in the medieval West through the concept of spontaneous order. In order to do this, in the first place, the notion of spontaneous order will be explained, as well as other related concepts, such as "institution" or "trade". In the second place, we will study some of the institutions that made medieval trade possible, including manors and the movements of the peace and truce of God. Finally, in the third place, medieval trade will be analysed as an spontaneous order, formed by phenomena such as markets and fairs, commercial contracts or merchants' organizations.
\end{abstract}

Keywords: medieval trade, spontaneous order, manors, peace and truce of God.

El objetivo de este artículo es ofrecer un marco interpretativo para analizar el crecimiento comercial que tiene lugar en el Occidente Medieval durante la plena Edad Media, entre los siglos XI y XIII. Durante estos siglos, nos encontramos con un proceso económico consistente en una proliferación de intercambios de carácter comercial. En este 
proceso, además, juegan un papel importante un conjunto de prácticas y organizaciones, como mercados y ferias regulares o contratos comerciales entre mercaderes o guildas. Fenómenos como estos son posibles, al menos en parte, debido a instituciones previas, como el señorío o como los movimientos de la paz y de la tregua de Dios. Es decir, señoríos e instituciones de paz forman una suerte de soporte para el comercio plenomedieval.

El comercio plenomedieval también se puede entender bajo el concepto de "orden espontáneo". Con esto, nos referimos a que la actividad mercantil y los fenómenos que la forman no están necesariamente dirigidos o planificados. Esto no quiere decir que algunos de sus elementos no lo estén, como sería el caso de un señor que construye la infraestructura para un mercado. Más bien, se trata de que el comercio es un orden social construido en base a la negociación y cooperación entre distintas personas y grupos sociales.

Nuestro objetivo, entonces, es analizar el comercio de la plena Edad Media a través del concepto de "orden espontáneo". También se recurrira a otras herramientas teóricas del ámbito de la economía política, como la noción de institución, partiendo de algunas ideas de autores como Friedrich Hayek, Israel Kirzner o Jack High. En este sentido, al enfoque histórico de este artículo se le suman algunas ideas de carácter socioeconómico. Es decir, se entenderá el comercio medieval en relación con la sociedad que lo rodea.

En este sentido, el fundamento de este trabajo es historiográfico, por cuanto se trata de realizar una aproximación teórica al desarrollo del comercio plenomedieval. Así, partiremos de la obra de historiadores como Henri Pirenne, Michael Postan o Dominique Barthèlemy, entre otros, como soporte para introducir los elementos conceptuales en torno a los que se articula este artículo.

Con estos elementos en mente, se explicarán, en primer lugar, las bases conceptuales de las que parte este trabajo, definiendo nuestra idea de comercio y conceptos como los de institución, el de estructura institucional o el de "orden espontáneo". En segundo lugar, profundizaremos en algunos de los pilares del desarrollo comercial de la plena Edad Media en el Occidente Medieval a través de dos instituciones: el señorío, y los sistemas normativos de los movimientos de la paz y de la tregua de Dios. Finalmente, en tercer lugar, interpretaremos algunas de las prácticas clave del comercio medieval a partir del concepto de "orden espontáneo", que es la matriz fundamental de este texto.

\section{CUESTIONES CONCEPTUALES: COMERCIO, INSTITUCIONES Y ORDEN ESPONTÁNEO}

Para empezar, conviene clarificar una serie de cuestiones en relación con los conceptos que se emplearán para analizar la actividad comercial entre los siglos XI y XIII. Una forma posible de entender el comercio plenomedieval es a través del concepto de "orden espontáneo". Así, se trataría de comprender el comercio como una forma de orden o de organización social que no está dirigida o planificada, al menos directamente. Se trataría, más bien, del resultado de las acciones más o menos voluntarias de distintos indi- 
viduos y grupos, aunque estos últimos también puedan ser grupos con poder. Es decir, el comercio plenomedieval sería el resultado de un proceso no dirigido por un sólo poder o un sólo grupo social (mercaderes, nobles o monarquía), sino que estaría conformado por distintas prácticas, instituciones u organizaciones (mercados, ferias, señoríos o guildas) que constituyen la base sobre la cual es posible comerciar. En este sentido, es conveniente aclarar una serie de conceptos:

a) En primer lugar, el propio concepto de "orden espontáneo", que nos sirve para definir el comercio medieval. La idea de "orden espontáneo" abarcaría los fenómenos sociales que, aunque manifiestan una cierta organización, no son el resultado de una planificación consciente. El orden económico es más bien el resultado de negociaciones, de adaptaciones a circunstancias diferentes (cambios en la cosecha o en la situación política), o el fruto de la repetición de una acción sucesivamente en el tiempo, hasta el punto en que se vuelve un hábito o una rutina. Por ejemplo, las fechas de los mercados y ferias plenomedievales, que en un primer momento se celebraban en días de festividad religiosa, responden a una adaptación a las circunstancias sociales de la plena Edad Media. En dichas festividades había más gente reunida y resultaba más fácil comerciar. Conforme aumenta el número de mercados y la población urbana, en cambio, los mercados y ferias periódicos se vuelven una práctica más habitual. Y este proceso no está ni dirigido ni directamente controlado por ningún agente (individual o colectivo) sino que participan en él, a su manera, mercaderes, campesinos, artesanos y señores (laicos y religiosos) ${ }^{2}$. Así, el comercio como "orden espontáneo" depende de la existencia de reglas, prácticas e instituciones que proporcionan un marco en el que los comerciantes, los señores o los campesinos actuan.

Partiendo de esto, entenderemos el comercio plenomedieval como un orden socioeconómico de corte espontáneo, formado por ciertas prácticas, instituciones y organizaciones (mercados, guildas, asociaciones contractuales). Y este orden estaría asentado en otros fenómenos sociales y políticos, como pueden ser los señoríos, las ciudades, o los movimientos de la paz y de la tregua de Dios, como veremos.

b) Para profundizar en la idea del comercio como "orden espontáneo", es útil clarificar el concepto de institución ${ }^{3}$, uno de los elementos más importantes del fenómeno

1 Véase Friedrich A. Hayek, Law, legislation and liberty, vol.1: Rules and order, Routledge, Londres, 1982, pp. 35-54.

2 Cabe distinguir entre la evolución más o menos espontánea de una institución y el carácter espontáneo de un orden social. Véase al respecto Stefano Moroni, "Two different theories of two different spontaneous phenomena: orders of actions and evolution of institutions in Hayek", Cosmos and Taxis, vol. 1, n. 2 (2014), pp. 9-23.

3 La bibliografía sobre el concepto de institución es bastante amplia. Véase Jack High, 'Entrepreneurship and economic growth: the theory of emergent institutions', Quarterly Journal of Austrian Economics, vol.12, n.3 (2009), pp.7-10; Peter Boettke, "Evolution and economics: Austrians as institutionalists", Research in the history of economic thought and methodology, vol. 6 (1989), pp. 73-89; Richard N. Langlois y Geoffrey M. Hogdson, "Orders and organizations: towards an Austrian theory of social institutions" en Bruce Caldwell y Stephen Boehm (eds.), Austrian economics: tensions and new 
comercial. Aquí definiremos institución como un conjunto de normas que regulan un tipo determinado de interacción social. El concepto de institución, así definido, abarcaría organizaciones como el señorío o la Iglesia. En este sentido, nos interesan las instituciones relacionadas con la producción ${ }^{4}$ y distribución de recursos, es decir, los aspectos económicos de las instituciones. Por ejemplo, los aspectos del señorío relacionados con el uso de la tierra y el pago de rentas, o las reglas que la paz y la tregua de Dios intentan promover respecto a la violencia sobre los mercaderes.

Si bien hay instituciones que pueden surgir a partir de la acción y planificación de algún agente con poder, como puedan ser reyes o nobles, aquí nos interesan las instituciones que emergen por otros medios. Cuando individuos y colectivos adoptan o inventan de forma más o menos voluntaria una práctica, una regla para la acción, o una forma de interacción determinada, pueden aparecer instituciones sin necesidad de planificación previa. Se trataría de una suerte de evolución espontánea de instituciones, en la cual no tiene por qué haber una imposición desde el poder. En buena medida, este es el caso de prácticas importantes para el comercio plenomedieval. Nadie diseñó las asociaciones de comerciantes (guildas) y las normas que las definen desde cero, sino que son el fruto de una larga evolución que se remonta al mundo carolingio, al menos ${ }^{5}$.

La aparición de estas formas de relacionarse es fruto de la negociación y de la cooperación, no de la planificación. Lo mismo ocurre con la adopción de dichas prácticas. Es posible que distintas personas y colectivos comienzan a regir su comportamiento siguiendo determinadas reglas debido a sus propios intereses (económicos, morales, culturales o políticos). Se trataría de un proceso de imitación, a partir de decisiones a nivel local. Algunos ejemplos podrían ser los cambios en las relaciones entre señores y campesinos (de renta en especie a renta en moneda), la negociación de los pactos de la paz de Dios en lugares concretos (Charroux, Narbona), o el establecimiento de un mercado regular. Fenómenos de este estilo pueden aparecer y extenderse a partir de la negociación y cooperación entre mercaderes, señores, Iglesia o campesinos, aunque no hay que descartar el rol del rey, por ejemplo. Y por supuesto, esto no quiere decir que no existan conflictos o ejercicio del poder en el establecimiento de este tipo de instituciones.

Finalizando con las instituciones, cabe destacar que estas no se dan en un vacío, sino que están siempre en relación unas con otras. Algunos fenómenos sociales presupo-

directions, Springer, New York. 1992, pp. 165-192. También resulta importante distinguir nuestra aproximación al concepto de institución del enfoque neoinstitucionalista. Véase al respecto el artículo de Joseph R. Stromberg, 'Douglass C.North and non-marxist institutional determinism', Journal of Libertarian Studies, vol.16, n.4 (2002), pp. 101-137.

4 Aquí entenderemos por producción la transformación de un bien en otro. Así, la producción no es necesariamente la creación de mercancías para el mercado, sino que la cosecha, o la creación de artefactos para uso propio también se englobarán bajo el concepto de producción.

5 Adrieen Verhulst, The rise of cities in North-West Europe, Cambridge University Press, Cambridge, 1999, pp. 123-125. 
nen la existencia de ciertas instituciones ${ }^{6}$. Pensemos por ejemplo en el caso de los contratos mercantiles como la commenda. Para que exista una práctica como este contrato, hacen falta otra serie de prácticas, como la existencia de moneda o mercados más o menos estables. De la misma forma, los mercados o ferias periódicos necesitan un entorno institucional que provea mecanismos para la resolución de conflictos, como forma de paliar los daños provocados por fraudes o robos. Los tribunales señoriales o el arbitraje jugarían este rol en el comercio plenomedieval. Así, las instituciones acaban formando una suerte de estructura, una red de reglas y comportamientos. Lo usual, además, es que esta red de normas dependa, en última instancia, de reglas de carácter muy general, como la idea de propiedad, o la prohibición el robo. En buena medida, el comercio medieval consistía en una estructura de este estilo. La existencia de mercados y ferias, gremios o guildas de mercaderes o diferentes formas contractuales dependía, al menos en parte, de la existencia de otras instituciones como los señoríos, las ciudades, o la paz de Dios.

c) Finalmente, podemos hablar del comercio plenomedieval como un fenómeno social que sobrepasa al intercambio de bienes materiales o moneda entre dos personas ${ }^{7}$. Más bien, entenderemos el comercio como un proceso social ${ }^{8}$. En este sentido, el comercio plenomedieval es un "orden espontáneo" que está conformado por múltiples prácticas, normas e instituciones. Estas crean un marco en el que es posible un intercambio más o menos voluntario de bienes. Por ejemplo, los mercados y ferias, que a veces dependen del señorío, son espacios en los que es posible comerciar siguiendo ciertas reglas. Estos espacios son partes fundamentales del comercio plenomedieval como "orden espontáneo". De la misma forma, organizaciones como las guildas proveen a los comerciantes de información y seguridad, como veremos. Así, el comercio medieval se convierte en un fenómeno complejo, constituido por múltiples instituciones y prácticas, y en un orden no

6 Jan W. Lindemans, 'Methodological individualism and cultural evolution: ontogenetic and phylogenetic approaches to social order', Quarterly Journal of Austrian Economics, vol.15, n.3 (2012), pp. 331-369. También cabe destacar el artículo de Friedrich Hayek ,Notes on the evolutions of systems of rules of conduct", republicado en Friedrich A. Hayek, Studies in philosophy, politics and economics, Routledge, Londres, 1967, pp. 66-81.

7 Destaquemos aquí la existencia de todo un debate sobre las formas de entender las economías no capitalistas. Existen aproximaciones de corte formalista, que consistirían en el uso de herramientas propias de la economía moderna (como la econometría, la idea de maximización del beneficio, o el concepto de costes de transacción) a la hora de analizar las economías anteriores a la Revolución Industrial y al capitalismo. Frente a estas, enfoques de carácter sustantivista defenderían que las economías premodernas no pueden ser analizadas con estos conceptos. Más bien, habría que entender como la distribución y producción de los recursos funcionaba en la sociedad del momento. Aquí se defenderá que ciertos conceptos de la economía política actual (como el de orden espontáneo) sí pueden aplicarse al comercio medieval, siempre que se tenga en cuenta el contexto social e institucional en el que se desarrolla este fenómeno. Para una crítica del formalismo, Francesco Boldizzoni, La pobreza de Clío, Crítica, Barcelona, 2003, y la reseña del mismo libro de Deirdre McClocksey, ,The poverty of Boldizzoni: resurrecting the German Historical School“, Investigaciones de historia económica, vol. 9 , n. 1 (2013), pp. 2-6.

8 En este sentido, se ha hablado del mercado como un proceso. Véase Israel Kirzner, "The entrepreneurial market process - an exposition”, Southern Economic Journal, vol. 83, n. 4 (2017), pp. 855-868. 
planificado, sino fruto de un desarrollo institucional en el que juegan un papel distintos grupos de la sociedad medieval (señores, campesinos, mercaderes o Iglesia).

Ahora bien, es conveniente matizar el propósito de este artículo. No se pretende convertir la noción de orden espontáneo en una noción totalizante, capaz de explicar el conjunto de la economía, o incluso el comercio, plenomedieval. Más bien, se trata de analizar ciertos aspectos del desarrollo de los intercambios económicos en la Edad Media, pero aspectos que no son los únicos relevantes a la hora de analizar estos fenómenos. Otras perspectivas bien podrían tener en cuenta otros factores como los demográficos, tecnológicos, o incluso las intervenciones de los monarcas, especialmente a partir del siglo XIII, que definitivamente, jugaron un rol importante en el comercio medieval ${ }^{9}$. Así, no se pretende establecer ningún tipo de primacía de un factor sobre los demás, sino más bien reflexionar sobre el comercio en base a los conceptos que venimos desarrollando, desde una perspectiva histórica e historiográfica.

\section{EL SEÑORÍO Y LA PAZ DE DIOS COMO EJEMPLOS DE INSTITUCIONES MEDIEVALES}

En el estudio de la economía medieval, uno de los elementos de mayor interés ha sido el crecimiento comercial de la Plena Edad Media. En este proceso se pondrían en relación el aumento de las cosechas y el incremento poblacional entre los siglos XI y XIII, así como la multiplicación de ciudades por el Occidente Medieval y la proliferación de mercados y ferias. Hay un paulatino aumento de los intercambios y una transformación en las formas en las que estos se producen. Nos referimos a que la actividad comercial se vuelve más compleja, más elaborada, implicando a un mayor número de personas y a nuevas instituciones y prácticas (nuevos tipos de contrato, sistemas complejos de ferias o organizaciones de mercaderes), como veremos. Con todo, un elemento central de este proceso es la aparición del excedente agrícola, es decir, de una cosecha mayor de la necesaria para la mera subsistencia ${ }^{10}$. Este excedente es el resultado de un proceso de cambio técnico en la agricultura a partir del siglo X, con la difusión del molino, la introducción

9 La intervención de las distintas monarquías en la economía medieval también es una cuestión compleja. Muestra de ello serían los debates en torno a la creación o no, por parte de Alfonso X, de la Mesta. Véase Enrique Rodríguez-Picavea Matilla, "La ganadería en la Castilla medieval: una revisión historiográfica", Medievalismo, vol. 8 (1998), pp. 111-153. La intervención también podía consistir en regulaciones en torno a la calidad de los productos en el mercado. En Inglaterra, por ejemplo, se establece un conjunto de normas respecto a la calidad y precios de la cerveza y el pan. Ahora bien, la aplicación de estas leyes parece haber dependido de circunstancias locales, adaptándose en los mercados y ciudades en cuestión. James Davis, Medieval market morality: life, law and ethics in the English marketplace, Cambridge University Press, Cambridge, 2012, pp. 231-251 y 368-377.

10 Robert S. López, The commercial revolution of the Middle Ages, 850-1350, Spectrum, New Jersey, 1971, pp.56-58. 
del arado de vertedera y de la rotación trienal ${ }^{11}$. Ahora bien, a la hora de interpretar todos estos fenómenos, que caracterizan el desarrollo comercial de entre los siglos XI y XIII, vamos a aplicar algunos elementos teóricos. Así, analizaremos algunas de las instituciones que permiten estos cambios, es decir, estudiaremos la estructura institucional que sirve como pilar para el orden comercial plenomedieval. Para ello, tomaremos como ejemplos los señoríos y los movimientos de la paz y la tregua de Dios:

a) A la hora de estudiar los orígenes del crecimiento económico plenomedieval, una de las instituciones centrales es la del señorío. Por una parte, este es el marco institucional en el que se da la producción de bienes agrícolas, que sostienen el crecimiento demográfico entre los siglos X y XIII. Por otra, los señoríos son una estructura política y jurisdiccional con mucho peso a la hora de potenciar, crear o regular mercados y ferias. En este sentido, el señorío forma parte del desarrollo institucional que hace posible el comercio plenomedieval. Durante la plena Edad Media, mercados y ferias pueden formar parte de la institución del señorío, por ejemplo. Estos espacios comerciales, precisamente, presuponen las reglas y prácticas que conforman el señorío (incentivos a la producción, rentas en moneda o justicia señorial $)^{12}$.

Emergiendo principalmente desde finales del siglo IX, con la caída del Imperio Carolingio, el señorío es el fruto de un proceso de fragmentación política y especialmente de la "atomización" de los tribunales de justicia ${ }^{13}$. La institución del señorío va de la mano

11 Para algunos de estos elementos véanse Henri Pirenne, Las ciudades en la Edad Media, Editorial Crítica, Barcelona, 1990; Robert S. López, The commercial revolution of the Middle Ages, 850-1350, Spectrum, New Jersey, 1971; Werner Rösener, Los campesinos en la Edad Media, Editorial Crítica, Barcelona, 1990; Robert Moore, La primera revolución europea, c. 970-1250, Editorial Crítica, Barcelona, 2003.

12 Douglass C. North y Robert P. Thomas han destacado la importancia del señorío para el desarrollo económico medieval pero desde una perspectiva diferente, véase Douglass C. North y Robert P. Thomas, El nacimiento del mundo occidental. Una nueva historia económica (900-1700), Siglo XXI, Madrid, 1978, especialmente el capítulo 4. Para ellos, el señorío es una institución que surge debido a las condiciones demográficas y económicas del momento. El señor proporciona justicia y seguridad, y las rentas o prestaciones personales son un simple pago por los servicios del señor. Por otra parte, que el señor ejerza la fuerza responde a la necesidad de evitar la figura del "free rider", personas que se beneficien de los servicios del señor sin pagarle. En este trabajo, se defiende, en cambio, que el señorío favorece al desarrollo comercial en comparación con períodos anteriores, y tal y como tuvo lugar en la Plena Edad Media. Robert Brenner critica este modelo en la nota 12 de Robert Brenner, "Estructura de clases agraria y desarrollo económico en la Europa preindustrial" en , Trevor H. Aston y Philpin, C.H.E. (eds.), El debate Brenner. Estructura de clases agraria y desarrollo económico en la Europa preindustrial, Crítica, Barcelona, 1988, pp. 28-29. Véase también Sheylagh Ogilvie, "Whatever is, is right? Economic institutions in preindustrial Europe", Economic History Review, vol. 60, n. 4 (2007), pp. 652-653. A lo largo del artículo, S.Ogilvie hace una crítica de las principales instituciones analizadas por autores neo- institucionalistas.

13 El señorío aparecería en algunas zonas del reino carolingio en el siglo VIII, pero para Chris Wickham no se extenderían por otras regiones como Italia, los Países Bajos o Inglaterra antes del siglo X. Véase Chris Wickham, Una historia nueva de la Alta Edad Media, 400-800, Crítica, Barcelona, 2009, p. 406. Cabe destacar que el proceso de surgimiento del señorío, así como el fenómeno de la "privatización" de los tribunales de justicia se enmarcaría dentro de todo un debate sobre el surgimiento del feudalismo, el debate sobre la revolución feudal, que enfrentaría a gradualistas contra mutacionistas. Véanse Dominique Barthélemy, El año mil y la paz de Dios. La Iglesia y la sociedad feudal, Universidad de 
del fortalecimiento de los poderes políticos locales (señores y monasterios), de forma que estos tienen un mayor margen de maniobra a la hora de imponer normas y prácticas. No se trata de un proceso homogéneo en todo el Occidente Medieval, sino que las circunstancias de diferentes regiones afectan a la emergencia de estas estructuras feudales. En este sentido, la creación de señoríos no fue igual en todas las regiones del Occidente Medieval. Por ejemplo, en Inglaterra, aunque se da un proceso similar entre 1000 y 1160, este convive con una monarquía estable y con un poder continuado. La llamada "privatización" del poder político en Italia era incompleta incluso a finales del siglo XI, y en lugares como Lombardía no hay crisis violentas. De hecho, en Italia, la existencia de una mayor urbanización le da al proceso de "atomización” un carácter peculiar, aunque las ciudades se "feudalizan" entre el 900 y el siglo XI. Pese a dichas peculiaridades, comparten ciertas características con el resto del Occidente Medieval, como la importancia de las relaciones privadas entre la nobleza, o la fragmentación del poder político ${ }^{14}$.

Todas estas circunstancias contribuyen a la producción de una realidad social e institucional de carácter "feudal" que afectará a las formas en las que se desarrolla el comercio en cuanto proceso social. La fragmentación política en la zona de Francia, por ejemplo, hace que los mercados formen parte, a menudo, de la institución del señorío, mientras que en Inglaterra el rey tiene un peso mayor en la institucionalización de mercados y ferias. Así, las formas del desarrollo comercial de la Plena Edad Media -es decir, las vías por las que se institucionalizan los mercados, por ejemplo- dependían de las instituciones existentes anteriormente.

El poder que los señores ejercen a nivel local en el marco del señorío, es decir, la fragmentación, permite un amplio margen de adaptación, cambio o incluso innovación en esta institución. El señorío aparece como un espacio en el que es posible introducir diferentes prácticas, ya sea a nivel técnico, como los ya mencionados arado de vertedera o roturaciones, como a nivel institucional, con los cambios en las relaciones coactivas entre señores y campesinos, como veremos. En este sentido, el señorío es, en parte, un ámbito de cambio en lo económico, así como de imitación de prácticas beneficiosas para señores, campesinos o ambos. Aquí tenemos que tener en cuenta los intereses de los señores, ya sea por motivos económicos, morales o de estatus, a la hora de permitir o incluso promocionar actividades económicas más productivas.

Los señores muestran un interés en las actividades económicas del señorío, potenciando el incremento de las cosechas. Por ejemplo, en regiones como Picardía, Flandes, Namur o Lieja, se comienzan a aprovechar materiales importantes en la producción

Granada; Universitat de València, Granada, 2005; Jean-Pierre Poly y Éric Bournazel, El cambio feudal (siglos X-XII), Editorial Labor, Barcelona, 1983; y Guy Bois, La Revolución del año mil. Lournand, aldea del Mâconnais, de la Antigüedad al feudalismo, Editorial Crítica, Barcelona, 1991.

14 Véase, por ejemplo, Chris Wickham, "La mutación feudal en Italia", en Antonio Malpica y Tomás Quesada, Los orígenes del feudalismo en el mundo Mediterráneo, Universidad de Granada, Granada, 1994, pp. 36-40; y Chris Wickham, 'Debate: the "feudal revolution”: IV', Past\&Present, vol.155 (1997), p. 199. 
del tinte. Algunos proyectos de expansión de la tierra cultivable necesitaban actividades como el drenaje de tierras, o grandes cantidades de instrumental, bestias y grano, que los campesinos no podrían conseguir por ellos mismos. De hecho, un señor, por sí sólo, podría no disponer de medios suficientes para llevar a cabo un proyecto como este, por lo que se aliaba con otros señores, como pasa con la explotación del bosque de Marigny en 1275 , realizada conjuntamente por tres caballeros ${ }^{15}$. El señorío supone un marco económico, institucional y social en el que se introducen prácticas que conducen a un aumento de la cosecha y se fomenta la elaboración de otro tipo de bienes, como el tinte.

Además, hay que tener en cuenta los progresivos cambios en la estructura económica del señorío, es decir, en las relaciones entre señores y campesinos ${ }^{16}$. En un primer momento las tierras del señorío estarían divididas entre la reserva señorial y el resto de las tenencias, en cuya gestión tienen más peso los campesinos, quienes, debido a la coerción ejercida por los señores, debían trabajar un día a la semana en la reserva señorial ${ }^{17}$. Sin embargo, entre los siglos X y XIII hay un proceso de cambio en la estructura económica del señorío que se caracteriza precisamente por la sustitución de las obligaciones de trabajo en la reserva señorial por el pago de una renta en especie o en moneda. En general, el pago de rentas es una imposición que permite al campesino más capacidad para gestionar su trabajo, aunque también beneficia directamente al señor. Esto podría permitir la introducción de prácticas más productivas. También se puede destacar la cuestión del pago de rentas en moneda, una relación más adaptada a la realidad comercial que implica a los señores en la actividad mercantil, especialmente en zonas con un comercio más intenso (Flandes, Norte de Italia). Así, los señores pagan jornaleros para trabajar la reserva, como en los viñedos de Cluny hacia 1150, y estos jornaleros a menudo son campesinos del propio señorío que complementan sus ingresos ${ }^{18}$. En este sentido, el señorío se adapta a la realidad social que lo rodea. Esto supone que señores y campesinos son capaces de introducir o imitar comportamientos que les resultan beneficiosos (rotación trienal, rentas en moneda) dado el contexto en el que se encuentran (auge comercial).

b) Otro proceso institucional que juega un papel interesante en el desarrollo comercial de la plena Edad Media es el movimiento de la paz de Dios. Con estos movimientos se demuestra que cierta estabilidad institucional o seguridad jurídica puede favorecer el

15 Ronald G. Witt, "The landlord and the economic revival of the Middle Ages in Northern Europe, 10001250", American Historical Review, vol.76, n.4 ( 1971), pp. 970-977.

16 Marc Bloch, La sociedad feudal, Akal, Madrid, 2002, pp. 259-265.

17 Georges Duby, Guerreros y campesinos. Desarrollo inicial de la economía europea, 500-1200, Siglo XXI, Madrid, 1987, pp.104-107. Ahora bien, las obligaciones de los campesinos podían ser muy variadas, dependiendo de su estatus. Véase Jean-Pierre Poly y Éric Bournazel, El cambio feudal (siglos $X$-XII), Editorial Labor, Barcelona, 1983, pp.127-153.

18 Ronald G. Witt, "The landlord and the economic revival of the Middle Ages in Northern Europe, 10001250", American Historical Review, vol.76, n.4 ( 1971), pp.973-974. Para más ejemplos de cambios en las obligaciones de los siervos véanse Michael M. Postan, Essays on medieval agriculture and general problems of the medieval economy, Cambridge University Press, Cambridge, 1973, pp. 93-94; y Marc Bloch, La sociedad feudal, Akal, Madrid, 2002, pp. 262-264. 
incremento de la actividad comercial. En parte, un entorno estable podría permitir que mercaderes o campesinos se formaran expectativas correctas acerca de dónde comerciar, en qué circunstancias y las posibilidades de sufrir violencias más o menos arbitrarias, como robos, y fraudes, que aumentarían demasiado los costes de la actividad mercantil. Esto no quiere decir que no existieran robos, fraudes y asesinatos los mercados. Ahora bien, sí que existe una institucionalización de normas generales respecto al uso de la violencia por parte de los movimientos de la paz y de la tregua de Dios. Estas normas son uno de los factores que podría explicar el despliegue comercial plenomedieval.

Así, el movimiento de la paz de Dios consiste en un conjunto de concilios en los que se acordaba evitar violencias de carácter arbitrario (asesinatos, robos, destrozos de propiedades $)^{19}$. Este movimiento y las normas que promueve son más el resultado de una negociación, de un juego de intereses, que de una suerte de imposición desde el poder. El punto culminante de los concilios consistía en el juramento de un acuerdo, de forma que el pacto era un rasgo central de las instituciones de paz. Además, en la expansión y evolución del movimiento juega un papel importante la imitación y la adaptación. En un primer momento, en el Mediodía francés a finales del siglo X, los juramentos eran de por vida, mientras que, en Borgoña y Provenza, hacia 1021-1022 los juramentos durarían únicamente siete años ${ }^{20}$. Uno de los puntos principales de estos concilios, aparte la protección de campesinos, o la prohibición de extender las jurisdicciones señoriales en tierras de la Iglesia, sería la insistencia en la seguridad de los mercaderes y los bienes. Así, estamos hablando de unas de esas reglas generales que permitirían el desarrollo de instituciones comerciales.

En otro sentido, habría que clasificar las asambleas y concilios del movimiento de la paz de Dios dentro de nuestro concepto de instituciones espontáneas. Por una parte, las reglas y pautas de comportamiento son fruto de negociaciones entre señores y miembros del clero a menudo, sin que necesariamente haya elementos coercitivos fuertes en estos acuerdos. Así, por ejemplo, en Melle, tras una asamblea de paz en 1302, un señor, Gualterio ataca al monasterio de San Majencio en 1044, pero finalmente se arrepiente y dona diversos bienes de su señorío, tras un acuerdo con los monjes ${ }^{21}$. Así, las instituciones de paz son el fruto de acuerdos, negociaciones y pactos de carácter local. Son formas de coordinación - de establecimiento de normas y formas de conducta- que no se imponen

19 El fenómeno de la violencia, y por tanto la cuestión de los concilios de Paz están muy relacionados con el debate sobre la revolución feudal. Véase el artículo de Thomas N. Bisson, "The "feudal revolution"”, Past\&Present, vol.142 (1994)pp. 6-42, y las respuestas de Dominique Barthélemy, "Debate: the "feudal revolution": I", Past\&Present, vol.152 (1996), pp. 196-208; Stephen D. White, "Debate: the "feudal revolution": II", Past\&Present, vol.152 (1996), pp. 197-205; y Chris Wickham, "Debate: the “feudal revolution": IV", Past\&Present, vol.155 (1997), pp. 196-208.

20 Jean-Pierre Poly y Éric Bournazel, El cambio feudal (siglos X-XII), Editorial Labor, Barcelona; Calabria, 1983, pp. 164-167.

21 Dominique Barthélemy, El año mil y la paz de Dios. La Iglesia y la sociedad feudal, Universidad de Granada; Universitat de València, Granada, 2005, pp. 478-481 
necesariamente desde un poder central. Al mismo tiempo, se da un proceso de imitación de este tipo de asambleas, de forma que, desde los primeros concilios en Charroux (989) y Narbona (990), el movimiento se extiende por el Limousin, Auvernia, Borgoña y Provenza. También se dan modificaciones en las reglas que buscan promocionar los concilios de paz. A partir de un sínodo en Elna de 1027, surge en Cataluña la tregua de Dios, proceso en el que se promueven normas juradas en concilios anteriores con la prohibición de la violencia los domingos. Esta tregua dominical se extiende a otras festividades, llegando a haber unos doscientos cincuenta días al año en los que está prohibida la violencia señorial $^{22}$. Esta creación de unos tiempos en los que la violencia está prohibida tendrá sus efectos en el entramado comercial de la Edad Media. Estos tiempos de tregua y paz, por ejemplo, pueden facilitar la aparición de mercados y ferias los domingos, por ejemplo. Los movimientos de paz también desarrollan su contenido en relación con el comercio, insistiendo en la protección de los comerciantes, y de bienes económicos y en la importancia del pago de deudas. Así, los acuerdos de la paz y de la tregua de Dios, que incluyen normas como la prohibición de la violencia o la protección de los mercaderes, constituyen una realidad institucional compleja que favorece la actividad comercial.

Las normas que venimos mencionando pueden considerarse el reflejo de un marco de valores generales que, en parte, facilita el comercio en cuánto "orden espontáneo" en la plena Edad Media. Se trataría de un marco normativo compartido por las comunas italianas y flamencas ${ }^{23}$. Estos valores se podrían considerar como uno de los pilares que forman el soporte del comercio plenomedieval. El caso de los mercados y ferias periódicos, que solían coincidir con días de tregua, formaría parte de este proceso. Asimismo, de darse un proceso de pacificación, este tendría efectos económicos, ya que reduciría la incertidumbre.

\section{EL ORDEN ESPONTÁNEO COMO MOTOR DEL COMERCIO MEDIEVAL}

Los señoríos y los movimientos de paz forman parte de la base sobre la que, entre los siglos XI y XIII, se desarrollará el comercio medieval. El despliegue del comercio es,

22 Dominique Barthélemy, El año mil y la paz de Dios. La Iglesia y la sociedad feudal, Universidad de Granada; Universitat de València, Granada, 2005, pp. 597-508.

23 Chris Wickham, "La mutación feudal en Italia", en Antonio Malpica y Tomás Quesada, Los orígenes del feudalismo en el mundo Mediterráneo, Universidad de Granada, Granada, 1994, pp.44-57. En Flandes, las comunas adoptaron un lenguaje similar al de la paz de Dios, denominando su organización amicitia. Véase Geoffrey G. Koizol, "Monks, feuds and peace making in eleventh century Flandes", Historical Reflections, vol.14, n.3 (1987), pp. 548-549. En este sentido, también se puede destacar la posición de Michael Mann, que afirma que el cristianismo actúa como un sistema normativo, promoviendo una "pacificación normativa". Véase Michael Mann, The sources of social power. Vol.I: a history of power from the beginning to A.D.1760, Cambridge University Press, Cambridge, 1986, especialmente el capítulo 12, pp. 373-416. 
con todo, un fenómeno contingente. Es decir, no hay un proceso mecánico por el cual la construcción de la actividad comercial sea un resultado necesario a partir de instituciones como el señorío o los concilios de la paz y de la tregua de Dios. Más bien, distintos individuos y grupos contribuyen, a su manera, a conformar el proceso comercial. Es en este sentido en el que el comercio medieval es un "orden espontáneo" en el que están presentes los intereses de distintos grupos sociales. Así, la actividad mercantil plenomedieval está formada por mercaderes que negocian en las ferias de Champaña, campesinos que venden una parte de su cosecha en un mercado rural, o señores que construyen infraestructuras para promover un mercado incipiente. Ahora bien, hay ciertos fenómenos sociales y económicos que son centrales a la hora de coordinar las acciones e intereses de mercaderes, señores y campesinos. Estamos hablando de espacios comerciales como los mercados y las ferias, de prácticas como los contratos entre mercaderes o de organizaciones como las guildas. Mercados, contratos y organizaciones forman parte del comercio medieval como "orden espontáneo". Así, a partir de esta idea, analizaremos ahora el papel de los mercados y ferias, el caso de las ferias de Champaña, y los contratos y organizaciones de los mercaderes:

a) Los mercados y las ferias son espacios comerciales de gran relevancia dentro del "orden espontáneo" del comercio medieval. Son centrales en el proceso de comercialización ${ }^{24}$ que experimenta la sociedad medieval entre los siglos XI y XIII. Esta centralidad se debe a la multiplicación ${ }^{25}$ de este tipo de fenómenos, y a que estos consisten en espacios en los que pueden participar amplias capas de la población medieval. El surgimiento de estos no está dirigido por el poder, sino que es el resultado de múltiples interacciones entre individuos y grupos sociales, es decir, es el resultado de un proceso espontáno. Además, como ya se ha afirmado, los mercados y ferias, como parten del orden comercial de la Plena Edad Media, tienen como algunos de sus pilares, al señorío y a las normas extendidas por la Paz de Dios, aunque posiblemente no de forma exclusiva.

Un ejemplo que muestra el carácter dependiente de ferias y mercados es el de su relación con los movimientos de paz. Estos espacios comerciales forman parte de un "orden espontáneo" (el comercio) que, en parte, tiene por base a instituciones religiosas. Desde un momento temprano, se asocian los primeros mercados con los espacios y tiempos religiosos. Es decir, estos primeros mercados informales se celebrarían en lugares cercanos a iglesias (cementerios o atrios) y en festividades religiosas. No en vano, la palabra feria en latín, designa una festividad. Las festividades religiosas o el culto a los santos en las vigilias generarían un lugar y un día predecible para la agrupación de un buen número de personas, algo que diversos agentes económicos, desde artesanos locales hasta

24 El concepto de "comercialización" ha sido especialmente importante en la historiografía inglesa. Véase Richard Britnell, The commercialisation of English society, 1000-1500, Manchester University Press, Manchester, 1996.

25 Véase, por ejemplo, para el caso inglés, el artículo de James Masschaele, "The multiplicity of markets reconsidered", Journal of historical geography, vol.20, n.3 (1994), pp. 255-271. 
mercaderes ambulantes, aprovechan para llegar a un mayor número de compradores. El surgimiento de los mercados y ferias es el resultado, entonces, de las decisiones concretas de multiples individuos, desde mercaderes o campesinos, a figuras de poder, como señores laicos o eclesiásticos. Además, algunos de estos rasgos son compartidos por todo el Occidente Medieval: Inglaterra, Normandía, Italia, Flandes, Picardía ${ }^{26}$.

La conexión con espacios religiosos apunta a la idea de que la paz de Dios asienta un entramado normativo que permite el crecimiento de la actividad comercial, en parte a través de la creación de espacios apropiados para la aparición de mercados y ferias. En este sentido, no es sorprendente que los mercados se celebrasen en fechas importantes en el calendario cristiano, ya que estas, al igual que los domingos, estaban protegidas en la normativa extendida por el movimiento de la paz y la tregua de Dios. De la misma manera, los espacios, muy próximos a los templos, también gozaban de la misma protección. Además, hemos visto, como las asambleas de la tregua de Dios insisten en la protección de los mercaderes y sus bienes. Se trata de una normatividad que apunta a uno de los pilares claves de la actividad comercial, a la seguridad. Para que se realicen acciones de carácter mercantil, es necesario, cierta certidumbre, ciertas expectativas de que no van existir agresiones arbitrarias contra una persona y sus bienes. Por supuesto, esto no quiere decir que estos movimientos redujeran la violencia de una manera abrumadora, ni que las normas que prescriben fuesen totalmente originales. Es perfectamente posible que esta normatividad sea el fruto de un desarrollo gradual anterior, y que las asambleas de paz no sean más que una institución sintomática de ese fenómeno. Sea cual sea su origen, hay una normatividad que favorece el desarrollo comercial y crea un entramado institucional que actúa sobre dicho orden comercial, al crear, por ejemplo espacios y tiempos en los que la actividad comercial está protegida.

En otro orden de las cosas, el señorío también juega un papel importante en el desarrollo de mercados y ferias. Esto se debe, fundamentalmente, a los intereses, ya sean económicos o de otro tipo, que tenían los señores en el desarrollo de mercados en sus dominios. Los señores podían potenciar la existencia de mercados protegiendo la actividad comercial y proporcionando formas de resolución de conflictos. Así, por ejemplo, en Fauquembergues, en el norte de Francia, hacia 1220, el señor acuerda proteger a los

26 Algunos ejemplos de mercados y ferias celebrados en domingos y festividades del calendario cristiano, así como cercanos a espacios religiosos pueden encontrarse en Lucien Musset, "Foires et marchés en Normandie à l'époque ducale", Annales de Normandie, vol.26, n.1 (1976), p.8; Giovanni Cherubini, "Foires et marchés dans le campagnes italiennes au Moyen Âge" en Christian Desplat (ed.), Foires et marchés dans les campagnes de l'Europe médiévale et moderne. Actes des XIVes Journées Internationales d'Histoire de l'Abbaye de Flaran, Septembre, 1992, Presses universitaires du Mirail, Toulouse, 1996, pp. 80-82; Adrieen Verhulst, The rise of cities in North-West Europe, Cambridge University Press, Cambridge, 1999, pp.72-73; Richard Britnell, "The proliferation of markets in England, 1200-1349", Economic History Review, vol.34, n.2 (1981), pp. 209-221; y Robert Fossier, "Le probléme des marchés locaux en Picardie aux XIe et XIIe siècles", en Christian Desplat (ed.), Foires et marchés dans les campagnes de l'Europe médiévale et moderne. Actes des XIVes Journées Internationales d'Histoire de l'Abbaye de Flaran, Septembre, 1992, Presses universitaires du Mirail, Toulouse, 1996, pp. 15-26. 
mercaderes que se reúnen los jueves en el atrio de la Iglesia y en la plaza del mercado ${ }^{27}$. La administración del señorío también puede ayudar al establecimiento y crecimiento de mercados y ferias asumiendo costes de infraestructuras, como puestos de venta ${ }^{28}$. Esto podía funcionar a menudo en acuerdo con otros agentes económicos, como artesanos, ya que se construían parcelas alrededor de mercados, para el asentamiento de profesionales dedicados a la producción artesanal. El interés de los señores en la actividad comercial no se manifiesta únicamente en los mercados rurales, sino también en los asentamientos urbanos, en los que los señores tienen un importante peso. Así, la ciudad de Halesoween, en Inglaterra, recibe privilegios urbanos por parte de sus señores, la abadía de Halesoween, a finales del siglo XIII. Estos privilegios potencian el comercio de la villa, que ya tenía un mercado y una feria desde 1220. Lo mismo ocurre con unas veinticinco pequeñas ciudades formadas en las West Midlands, también en Inglaterra, entre los siglos XI y $\mathrm{XIV}^{29}$. En este sentido, los señores seculares y monásticos tenían interés en promocionar el crecimiento urbano, en parte debido a los ingresos que obtenían en forma de tasas por el acceso a mercados y ferias.

Los señoríos juegan un rol importante en el proceso de despliegue comercial de la Plena Edad Media, no sólo como un factor que podríamos llamar exógeno, incentivando la demanda ${ }^{30}$, sino promocionando de manera activa mercados y ferias, al proporcionar infraestructura, creando marcos institucionales (protección) o negociando el gobierno de ciudades mientras se mantuvieran las rentas que se extraían de diversas formas de actividad económica. En este sentido, el carácter fragmentado del poder juega un rol, al basarse muchas de sus decisiones en circunstancias locales e intereses negociados (entre gobiernos urbanos y señores, por ejemplo). Y tener mercados en su jurisdicción podía resultar beneficioso para un señor, ya fuese en términos económicos (el señor tendría acceso a recursos que proporcionan mercados y ferias) o sociales (un mayor estatus debido a mayores rentas) $)^{31}$.

27 Robert Fossier, "Le probléme des marchés locaux en Picardie aux XIe et XIIe siècles", en Christian Desplat (ed.), Foires et marchés dans les campagnes de l'Europe médiévale et moderne. Actes des XIVes Journées Internationales d'Histoire de l'Abbaye de Flaran, Septembre, 1992, Presses universitaires du Mirail, Toulouse, 1996, p. 23. Juega un factor importante, para R. Fossier, la paz mantenida alrededor de la iglesia, para el desarrollo de los intercambios en este lugar, que él denomina paix du village.

28 Richard Britnell, "The proliferation of markets in England, 1200-1349", Economic History Review, vol.34, n.2 (1981), pp. 209-219. Véase también Richard Britnell, "English markets and royal administration before 1200", Economic History Review, vol.31, n.2 (1978), pp.181-196, en el que se destaca la relación de los mercados con otras formas administrativas, como los Hundred.

29 Rodney Hilton., English and French towns in feudal society. A comparative study, Cambridge University Press, Cambridge, 1992, pp. 33, 53-55; y Rodney Hilton, "Small town society befote the Black Death", Past\&Present, vol.105 (1984), pp. 56-58.

30 Adrieen Verhulst, The rise of cities in North-West Europe, Cambridge University Press, Cambridge, 1999, p. 58.

31 En efecto, Steven R. Epstein ha destacado que, en la Baja Edad Media, parte del éxito de las ferias regionales se debía a que cualquiera que quisiera embarcarse en la actividad comercial, ya fuera por prestigio o ingresos, se podría beneficiar de ella. Véase Steven R. Epstein, "Regional fairs, institutional 
En definitiva, los mercados y ferias medievales son un elemento central del comercio plenomedieval, al constituir espacios en los que es posible los intercambios. Sus orígenes, además, muestran su relación con diversos fenómenos sociales. Desde mercaderes o campesinos que intercambiaban sus bienes en ellos, a instituciones religiosas que promovían un espacio de paz, pasando por el propio señorío, que podía tener jurisdicción sobre el mercado. En este sentido, los mercados y ferias son parte de un "orden espontáneo", resultado de negociaciones y coordinación de los intereses de múltiples partes.

b) El ejemplo de las ferias de Champaña puede mostrar el carácter del comercio medieval como un "orden espontáneo", es decir, no dirigido o no directamente controlado. Las ferias de Champaña fueron uno de los mayores centros comerciales del Occidente Medieval entre finales del siglo XII y principios del XIV. Estas ferias tenían un carácter espontáneo -no directamente planificado-, y negociado -ya que su regulación responde a acuerdos entre señores y mercaderes-. Asimismo, las ferias de Champaña, como veremos, son capaces de adaptarse a las circunstancias que las rodean. Estos son rasgos definitorios de un "orden espontáneo".

Estas ferias, en su momento más álgido (el siglo XIII), consistían en un complejo sistema de comercio en cuatro localidades de la región francesa. Había dos ferias en la ciudad de Troyes, otras dos en la de Provins, una en Lagny y otra en Bar-sur-Aube, cada una en un momento del año. Pero si bien en el siglo XIII la actividad comercial en estos lugares alcanza un elevado grado de sofisticación y complejidad, así como de coordinación y internacionalización, su origen es más humilde ${ }^{32}$. Se trataría de mercados rurales que aparecen de forma más o menos informal entre los siglos X y XII, como son las casos de Provins y Troyes o Bar-sur-Aube, respectivamente. Debido a su enclave, entre Flandes e Italia, estos mercados experimentan un proceso de crecimiento y complejización hasta convertirse en un complejo comercial de seis ferias (dos en Troyes y en Provins) regulares, de forma que durante todo el año había actividad mercantil en alguna zona de Champaña ${ }^{33}$.

En el crecimiento de las ferias de Champaña juegan un papel importante aspectos económicos y políticos. Uno de los factores que impulsa este proceso es la demanda de las cortes de Brie y Champaña, situadas en Provins y Troyes, lo que potenciaría el comercio a larga distancia ${ }^{34}$. Además, durante el siglo XII, los condes de Champaña muestran

innovation and economic growth in Late Medieval Europe", Economic History Review, vol.47, n.3 (1994), p. 471.

32 Robert H. Bautier, "The fairs of Champagne", en Rondo Cameron (ed.), Essays in French Economic History, Richard D. Irwin Inc., Homewood, 1970, pp. 46-47. Véase también Henri Pirenne, Historia económica y social de la Edad Media, Fondo de Cultura Económica, México D.F., 1969, pp. 75-80.

33 Charles Verlinden, "Markets and fairs", en Michael M. Postan, E.E. Rich. y Edward Miller (eds.), The Cambridge economic history of Europe from the decline of the Roman Empire. Vol.3: economic organisation and policies in the Middle Ages, Cambridge University Press, Cambridge, 1963, pp. 126-127.

34 Peter Spufford, Power and profit: the merchant in medieval Europe, Thames \& Hudson, London, 2002, pp. 143-144. 
un activo interés en las ferias. Así, se impulsarían salvoconductos para garantizar la seguridad de los mercaderes que viajaban a las ferias. En este sentido, se está proporcionando un entorno institucional que permite el desarrollo de la actividad mercantil. Otros elementos serían las bajas tasas de las ferias, que incentivaban la participación en las mismas, o las negociaciones con otros señores, como los duques de Borgoña o los condes de Flandes, para garantizar la seguridad de aquellos mercaderes de estas regiones que pretendían participar en las ferias ${ }^{35}$. Así, los intereses de señores los llevan a desplegar una serie de normas que facilitan la actividad económica (tasas bajas o salvoconductos) que los mercaderes aprovechan. En este sentido, las ferias se presentan como un orden comercial de corte espontáneo, cuya evolución responde a la actividad de miembros de distintos estratos sociales, sin que exista una planificación directa del fenómeno económico.

c) Entre los elementos que conforman el comercio plenomedieval en cuanto "orden espontáneo", tienen también relevancia las asociaciones de mercaderes. Se trataría de organizaciones como las guildas o las prácticas contractuales, que tendrían el rol de establecer formas de resolver conflictos o proporcionar recursos. La acción de los mercaderes no dependía exclusivamente de la acción de los señores, sino que, conforme se produce una relativa "comercialización" de la sociedad plenomedieval, y las formas de actividad mercantil se vuelven cada vez más complejas, los mercaderes empiezan a desarrollar sus propias formas de interacción y sus organizaciones particulares. Así, estas organizaciones (guildas) o contratos (commenda) pasan a formar parte del complejo orden comercial de la plena Edad Media. El papel de los mercaderes es particularmente activo. Estos desarrollan progresivamente estrategias para solucionar posibles problemas de seguridad, superar dificultades relacionadas con la pérdida de capital o formar redes sociales de apoyo mutuo. Además, estos fenómenos (guildas, tipos de contratos, u otro tipo de estructuras) no son el producto de una planificación clara, sino más bien, el resultado de una evolución social y de una adaptación a las diferentes circunstancias que surgen a medida que el comercio se expande, o de la resolución de conflictos derivados de la interacción con otros grupos sociales.

En los inicios del despegue comercial plenomedieval, los mercaderes solían juntarse en compañías, viajando juntos y armados, para solventar los problemas de seguridad que se podían presentar en la actividad comercial, especialmente en la larga distancia ${ }^{36}$. La agrupación de mercaderes también servía para propiciar la acumulación de capital. Esto es claro, en el caso de las asociaciones de Piacenza, muy presentes en Champaña en el siglo XIII, y muy relacionadas entre ellas debido a los lazos de parentesco entre un

35 Robert H. Bautier, "The fairs of Champagne", en Rondo Cameron (ed.), Essays in French Economic History, Richard D. Irwin Inc., Homewood, 1970, pp. 48-50, y Peter Spufford, Power and profit: the merchant in medieval Europe, Thames \& Hudson, London, 2002, pp. 146-147.

36 Henri Pirenne, Historia económica y social de la Edad Media, Fondo de Cultura Económica, México D.F., 1969, pp. 72-75. 
buen número de familias ${ }^{37}$. En este sentido, el parentesco forma parte de las instituciones que influyen en el desarrollo de las relaciones comerciales entre los siglos XI y XIII.

Pero quizás tengan más interés las diferentes formas contractuales que se desarrollan especialmente en Italia. La constante interacción entre mercaderes y las dificultades del comercio a larga distancia crean un ambiente ideal en estas regiones para el desarrollo de contratos complejos, capaces de resolver o minimizar dichas dificultades ${ }^{38}$. Estos contratos (rogadia, commenda) emergen de forma gradual, y se adaptan a los intereses de los agentes involucrados. Así, la flexibilidad y las posibilidades que ofrecen estos tipos de contratos a los mercaderes a la hora de enfrentarse a ciertos problemas económicos son uno de los elementos que pueden explicar su éxito. Es decir, diferentes tipos de contratos podían usarse en distintas situaciones, generando obligaciones variadas. El contrato rogadia, por ejemplo, consistía en que un mercader transportara y vendiera lo bienes de otros, que pasaría a deberle un favor similar. En el contrato colonna se daría una división de riesgos y beneficios, acordada antes de emprender un viaje. Destaca también el compagnia, una asociación de mercaderes que proporciona capital y trabajo, en la que los diferentes comerciantes, van alternando los roles de "principal" y "agente" 39 .

Tiene especial interés el contrato commenda, que era el más importante para el comercio a larga distancia. Era el fruto de una evolución jurídica a partir de tradiciones islámicas, judías, bizantinas y romanas. Este contrato consistía en una asociación entre dos mercaderes en el que uno aporta capital o bienes (commendator) y otro (tractator) viaja y vende las mercancía. Los beneficios se dividirían en tres cuartas partes para el commendator y una cuarta parte para el tractator. Existirían varias alternativas a este esquema. El tractator podía aportar parte de la inversión en bienes o capital, para obtener mayor parte de los beneficios, o incluso podía entrar en varias asociaciones de este tipo al mismo tiempo, de forma que el viaje de negocios interesa a múltiples mercaderes al mismo tiempo ${ }^{40}$.

Además de la flexibilidad, la expansión de estas formas contractuales hacia el noroeste del Occidente Medieval muestra el carácter emergente de estas instituciones, ya

37 Sheylagh Ogilvie, Institutions and European trade. Merchant guilds, 1000-1800, Cambridge University Press, Cambridge, p. 331.

38 La flexibilidad de los tipos de contratos en las asociaciones de mercaderes facilitaba enormemente los negocios a los mercaderes italianos al comerciar en las ferias de Champaña, llegando a tejer complicadas redes contractuales. Los mercaderes genoveses manejaban una gran cantidad de agentes que comerciaban por ellos cuando era necesario, comunicándose por correos privados. Véase R.D. Face, "Techniques of business between the Fairs of Champagne and the South of Europe in the twelfth and thirteenth Centuries", Economic History Review, vol.10, n.3 (1958), pp. 427-438.

39 Sheylagh Ogilvie, Institutions and European trade. Merchant guilds, 1000-1800, Cambridge University Press, Cambridge, pp. 334-335; y Robert S. López y Irving W. Raymond, Medieval trade in the mediterranean world: illustrative documents, Columbia University Press, New York, 2001, pp.185-186.

40 John H. Pryor, "The origins of the commenda contract", Speculum, vol.52, n. 1 (1977), pp. 12-21; y Raymond De Roover, "The organisation of trade", en Michael M. Postan, E.E. Rich. y Edward Miller (eds.), The Cambridge economic history of Europe from the decline of the Roman Empire. Vol.3: economic organisation and policies in the Middle Ages, Cambridge University Press, Cambridge, 1963, pp. $48-52$. 
que ejemplifica los procesos de imitación que son fundamentales para los fenómenos sociales emergentes. Así, estos contratos aparecen más tardíamente, hacia el siglo XIII, probablemente fruto del contacto con mercaderes italianos o del sur de Francia. Los mercaderes ingleses, posiblemente, verían las ventajas de este tipo de asociación, imitandolas. Así, por ejemplo, en Londres, a finales del siglo XIII, varios comerciantes vendían el vino de William Barache y Richard Hedreste al por menor, posiblemente en una asociación formada por un contrato commenda ${ }^{41}$.

Los contratos de este estilo se desarrollan para resolver diferentes problemas relacionados con la adquisición y gestión de recursos comerciales. En este sentido, prácticas como estas resultan fundamentales en la actividad comercial. Además, la variación y flexibilidad de estas prácticas muestran el carácter espontáneo del comercio medieval, al proporcionar formas de adaptarse a diferentes situaciones, sin necesidad de una planificación previa.

Las organizaciones de los mercaderes no se reducían a contratos de este tipo, sino que también existían diversas organizaciones de carácter más complejo y permanente cuyas reglas y prácticas ayudaban a evitar fenómenos como el fraude o el robo, un problema siempre presente en la actividad comercial. Estas agrupaciones, a mayores, generaban formas de acción colectiva, mediante las cuales los mercaderes podían negociar con autoridades urbanas y rurales o incluso con otros grupos de mercaderes. Se trata de organizaciones como las guildas, que tendrían un carácter espontáneo, siendo fruto de una larga evolución institucional.

El caso de las guildas de mercaderes es quizás especialmente claro. Con un origen que se remonta a ciertas asociaciones del mundo carolingio (lo que muestra su largo desarrollo institucional), las guildas eran organizaciones de mercaderes con diferentes obligaciones y derechos, en las cuales se entraba mediante un juramento. Estas obligaciones y derechos podían variar dependiendo de la organización en cuestión. En Saint-Omer y en Valenciennes, las guildas proporcionaban protección y asistencia mutua, especialmente en la pérdida de mercancías de forma arbitraria (confiscación, saqueo o accidente), ayuda en litigios en cortes extranjeras, y derechos y privilegios en mercados lugares. Asimismo, quizás como medio de legitimación o puede que por los orígenes religiosos de muchas de estas organizaciones, las guildas podían realizar acciones altruistas en sus ciudades de origen, como ayudar a los pobres o bien mantener las infraestructuras ${ }^{42}$.

Además, como ya mencionamos, las guildas sirven como forma de canalizar los intereses del colectivo de los mercaderes en las negociaciones con las autoridades políticas de determinados lugares. Esto además ayuda a entender el carácter emergente y espontáneo del orden comercial medieval, dependiente de una diversidad de instituciones

41 Michael M. Postan, Medieval Trade and Finance, Cambridge University Press, Cambridge, 1973, pp. 71-75.

42 Adrieen Verhulst, The rise of cities in North-West Europe, Cambridge University Press, Cambridge, 1999 , pp. 123-125. 
(autoridades políticas, mercados, guildas), de forma que no son producto de la voluntad de un único agente individual o colectivo. Las guildas proporcionaban distintos recursos para negociar en base a dichos intereses. Por ejemplo, los miembros de una guilda tenían prohibido comerciar en una ciudad en la que uno de sus miembros hubiese sido agredido, al menos hasta que se reparase el agravio cometido. Esta regla funcionaba también entre diferentes grupos de mercaderes. Así, los mercaderes flamencos no comerciaban con aquellos mercaderes ingleses que hubiesen estafado con el peso o la calidad de la lana ${ }^{43}$.

Con todo, la idea de que las guildas habrían sido muy positivas para el desarrollo comercial, tanto en la Edad Media como en la Edad Moderna, ha sido cuestionada ${ }^{44}$. Sin embargo, aparte de las guildas, existieron, desde el siglo XI, un amplio rango de mecanismos informales, cuasi-formales y formales, usados por los mercaderes para asegurar los contratos. Estos van desde el comercio en círculos de confianza (familia, comuna, o grupo cultural) al uso de "prendas" (propiedades, o incluso personas) en intercambios no simultáneos, pasando por el hospedaje. Este último, por ejemplo, funcionaba para asegurar la confianza en los mercaderes extranjeros. El mercader extranjero sería huésped de un mercader local, que se responsabilizaría de los pagos del foráneo, si es que este no cumplía los contratos que acordaba ${ }^{45}$. Este tipo de prácticas forman parte de la configuración del comercio medieval como "orden espontáneo". Su rol es especialmente importante en la reducción de la incertidumbre presente en el actividad comercial, en este caso en relación al cumplimiento de los contratos.

Asimismo, la negociación es una parte importante de estas instituciones. Esto se manifiesta en el uso del arbitraje como método de resolución de los conflictos. El arbitraje se caracterizaba por un acuerdo entre tres partes, las dos partes en conflicto y una que juzga el problema y propone una solución. Este último sería habitualmente un compañero mercader, elegido por las partes de forma consensuada, de la misma manera que los mercaderes en disputa también se pondrían de acuerdo en que código legal se aplicaría ${ }^{46}$. El arbitraje llega a estar presente también en las ferias de Champaña, donde los mercaderes podían elegir a quién acudir para solventar un problema. El carácter voluntario de la prác-

43 Avner Greif, Paul Milgrom y Barry R. Weintgast, "Coordination, commitment and enforcement: the case of the merchant guild", Journal of Political Economy, vol.102, n.4 (1994), pp. 750-755. Avner Greif es uno de los autores neo-institucionalistas que más ha trabajado el comercio plenomedieval. Desde este paradigma, ha destacado el papel de las autoridades políticas. Véase Avner Greif, "On the political foundations of Late Medieval Commercial Revolution: Genoa during the twelfth and thirteenth centuries", Journal of Economic History, vol. 54, n.2 (1994), 271-287.

44 En efecto, Sheyla Ogilvie en Institutions and European Trade. Merchant guilds, 1000-1800 rechaza la visión neo-institucionalista del comercio preindustrial, destacando la existencia de otras formas para solucionar los problemas del comercio, más allá de las guildas de mercaderes. Para esta autora, las guildas son instituciones que, aliadas con el poder político, monopolizaban un mercado, excluyendo a determinados grupos, y dañando el desarrollo comercial.

45 Sheylagh Ogilvie, Institutions and European trade. Merchant guilds, 1000-1800, Cambridge University Press, Cambridge, pp. 285-289.

46 Sheylagh Ogilvie, Institutions and European trade. Merchant guilds, 1000-1800, Cambridge University Press, Cambridge, pp. 297. 
tica del arbitraje muestra su carácter emergente, es decir, que se trata de un fenómeno no planificado, sino fruto de las elecciones de los agentes. En estas ferias, el arbitraje era más rápido y barato que otros sistemas de carácter oficial, y se usa con frecuencias, a menudo con testigos que habrían presenciado el contrato. En ocasiones, la Iglesia tiene un rol en esta forma de resolución de disputas, llegando a haber apelaciones al Papa, que nombraba a jueces que se encargaran del asunto. Y eran los guardas de las ferias los encargados de expulsar a los mercaderes que hubieran incumplido las condiciones del contrato ${ }^{47}$. Así, el arbitraje resulta ser, también una práctica de corte emergente, no controlada, sino producto de las interacciones más o menos voluntarias entre distintos agentes, en este caso entre los mercaderes en conflicto.

El comercio plenomedieval se configura entonces como un proceso cambiante, en el que diferentes prácticas, espacios u organizaciones emergen como respuesta a los problemas que asociados a la actividad mercantil: seguridad, demanda, creación de infraestructuras o problemas de coordinación. Instituciones como los mercados y las ferias resultan fundamentales a la hora de crear un espacio en el que es posible realizar intercambios, y estas instituciones se dan en marcos sociales determinados (como el señorío). En este sentido, se ve cómo emergen, a partir de un entorno institucional dado, orden comercial espontáneo, no dirigido, y de corte dinámico, que va cambiando conforme cambian las circunstancias.

\section{CONCLUSIONES}

A lo largo de este artículo se ha explicado cómo es posible entender el comercio plenomedieval a través de un marco de categorías en el que destaca la noción de "orden espontáneo". Así, se ha recurrido a diferentes conceptos como el de institución para entender elementos como la relación entre los señoríos o los movimientos de paz y fenómenos comerciales como los mercados y las ferias. Asimismo, se ha visto cómo ciertos elementos centrales para el comercio medieval, como las guildas de mercaderes o los contratos tienen un carácter espontáneo, es decir, surgen de la interacción de múltiples agentes persiguiendo sus intereses y se establecen como prácticas beneficiosas para los agentes que recurren a ellas. A partir de esto, el comercio plenomedieval se configura como un orden socioeconómico complejo, dependiente de múltiples factores que le dan forma, pero también como un fenómeno cambiante, que se adapta a las circunstancias que lo rodean. En definitiva, se trataría de un "orden espontáneo". En este sentido, esta

47 Robert H. Bautier, "The fairs of Champagne”, en Rondo Cameron (ed.), Essays in French Economic History, Richard D. Irwin Inc., Homewood, 1970, pp. 51-56. Por otra parte, se ha intentado analizar la eficiencia de este sistema desde la teoría de juegos, véase Douglass C. North, Paul R. Milgrom y Barry R. Weintgast, "The role of institutions in the revival of trade: the law merchant, private judges and the Champagne fairs", Economics and Politics, vol.2, n.1 (1990), pp. 1-23. 
perspectiva puede proporcionar un marco adecuado para la interpretación y análisis del comercio medieval.

Esta adecuación, nos parece, se produce a partir de varios puntos. En primer, es capaz de poner en relación, a través de la idea de estructura institucional, el comercio medieval con las instituciones que lo rodean, como el señorío. Ahora bien, en segundo lugar, esto se hace sin necesidad de presentar el comercio de forma estática, sino más bien, entendiendo el fenómeno como una realidad cambiante, que es modificada por las relaciones sociales que la rodean (como los movimientos de paz) pero también contribuye a la modificación de dichas realidades sociales (afectando, por ejemplo, a las relaciones entre señores y campesinos). Es decir, el concepto de "orden espontáneo" es capaz de poner en relación sociedad y actividad económica de una manera compleja. Y en tercer y último lugar, el enfoque que hemos utilizado en este trabajo puede dar cuenta del comercio sin reducir el fenómeno a una sola circunstancia (cambio demográfico o el papel de la moneda) sino que más bien es capaz de incluir diversos factores en la explicación del fenómeno comercial, desde los elementos que se han tratado, a otras cuestiones mencionadas, como la demanda, el aumento de la producción agrícola o incluso los marcos familiares que en muchas ocasiones proporcionan certidumbre a los mercaderes. 


\section{BIBLIOGRAFÍA}

Barthélemy, Dominique, El año mil y la paz de Dios. La Iglesia y la sociedad feudal, Universidad de Granada; Universitat de València, Granada, 2005.

Barthélemy, Dominique, "Debate: the 'feudal revolution': I", Past\&Present, vol.152 (1996), pp. 196-208.

Bautier, Robert H., "The fairs of Champagne”, en Rondo Cameron (ed.), Essays in French Economic History, Richard D. Irwin Inc., Homewood, 1970, pp. 42-64.

Bisson, Thomas N., "The 'feudal revolution'”, Past\&Present, vol.142 (1994), pp. 6-42.

Bloch, Marc, La sociedad feudal, Akal, Madrid, 2002.

Boettke, Peter, „Evolution and economics: Austrians as institutionalists“, Research in the history of economic thought and methodology, vol. 6 (1989), pp.73-89.

Bois, Guy, La Revolución del año mil. Lournand, aldea del Mâconnais, de la Antigüedad al feudalismo, Crítica, Barcelona, 1991.

Boldizzoni, Francesco, La pobreza de Clío, Crítica, Barcelona, 2003.

Brenner, Robert, "Estructura de clases agraria y desarrollo económico en la Europa preindustrial" en Trevor H. Aston y Philpin, C.H.E. (eds.), El debate Brenner. Estructura de clases agraria y desarrollo económico en la Europa preindustrial, Crítica, Barcelona, 1988, pp. 21-91.

Britnell, Richard, The commercialisation of English society, 1000-1500, Manchester University Press, Manchester, 1996.

Britnell, Richard, "The proliferation of markets in England, 1200-1349", Economic History Review, vol.34, n.2 (1981), pp. 209-221. https://doi. org/10.1111/j.1468-0289.1981.tb02063.x

Britnell, Richard, "English markets and royal administration before 1200", Economic History Review, vol.31, n.2 (1978), pp.181-196. https://doi. org/10.1111/j.1468-0289.1978.tb01140.x

Cherubini, Giovanni, "Foires et marchés dans le campagnes italiennes au Moyen Âge" en Christian Desplat (ed.), Foires et marchés dans les campagnes de l'Europe médiévale et moderne. Actes des XIVes Journées Internationales d'Histoire de l'Abbaye de Flaran, Septembre, 1992, Presses universitaires du Mirail, Toulouse, 1996, pp. 71-84.

Davis, James, Medieval market morality:life, law and ethics in the English marketplace, Cambridge University Press, Cambridge, 2012. https://doi.org/10.1515/hzhz-20160134

Duby, Georges, Guerreros y campesinos. Desarrollo inicial de la economía europea, 500-1200, Siglo XXI, Madrid, 1987.

Epstein, Steven R., "Regional fairs, institutional innovation and economic growth in Late Medieval Europe", Economic History Review, vol.47, n.3 (1994), pp. 459-482. https://doi.org/10.1111/j.1468-0289.1994.tb01386.x 
Face, R.D., "Techniques of business between the Fairs of Champagne and the South of Europe in the twelfth and thirteenth Centuries", Economic History Review, vol.10, n.3 (1958), pp. 427-438. https://doi.org/10.2307/2591262

Fossier, Robert “Le probléme des marchés locaux en Picardie aux XIe et XIIe siècles", en Christian Desplat (ed.), Foires et marchés dans les campagnes de l'Europe médiévale et moderne. Actes des XIVes Journées Internationales d'Histoire de l'Abbaye de Flaran, Septembre, 1992, Presses universitaires du Mirail, Toulouse, 1996, pp. 15-26.

Greif, Avner; Paul Milgrom y Barry R. Weintgast, "Coordination, commitment and enforcement: the case of the merchant guild", Journal of Political Economy, vol.102, n.4 (1994), pp. 745-776. https://doi.org/10.1086/261953

Greif, Avner, "On the political foundations of Late Medieval Commercial Revolution: Genoa during the twelfth and thirteenth centuries", Journal of Economic History, vol.54, n.2 (1994),pp. 271-87. https://doi.org/10.1017/s0022050700014479

Hayek, Friedrich A., Law, legislation and liberty, vol.1: Rules and order, Routledge, Londres, 1982.

Hayek, Friedrich A., Studies in philosophy, politics and economics, Routledge, Londres, 1967.

High, Jack, 'Entrepreneurship and economic growth: the theory of emergent institutions', Quarterly Journal of Austrian Economics, vol.12, n.3 (2009), pp. 3-36.

Hilton, Rodney, English and French towns in feudal society. A comparative study, Cambridge University Press, Cambridge, 1992.

Hilton, Rodney, "Small town society befote the Black Death", Past\&Present, vol.105 (1984), pp. 53-78. https://doi.org/10.1093/past/105.1.53

Kirzner, Israel, „The entrepreneurial market process - an exposition“, Southern Economic Journal, vol. 83, n. 4 (2017), pp. 855-868. https://doi.org/10.1002/soej.12212

Koizol, Geoffrey G., "Monks, feuds and peace making in eleventh century Flandes", Historical Reflections, vol.14, n.3 (1987), pp. 531-549.

Langlois, Richard N. y Geoffrey M. Hogdson, "Orders and organizations: towards an Austrian theory of social institutions" en Bruce Caldwell y Stephen Boehm (eds.), Austrian economics: tensions and new directions, Springer, New York, 1992, pp. 165-192. https://doi.org/10.1007/978-94-011-2186-6_6

Lindemans, Jan W. 'Methodological individualism and cultural evolution: ontogenetic and phylogenetic approaches to social order', Quarterly Journal of Austrian Economics, vol.15, n.3 (2012), pp. 331-369.

López, Robert S., y Irving W. Raymond, Medieval trade in the mediterranean world: illustrative documents, Columbia University Press, New York, 2001.

López, Robert S., The commercial revolution of the Middle Ages, 850-1350, Spectrum, New Jersey, 1971.

Mann, Michael, The sources of social power. Vol.I: a history of power from the beginning to A.D.1760, Cambridge University Press, Cambridge, 1986. 
Masschaele, James, "The multiplicity of markets reconsidered", Journal of historical geography, vol.20, n.3 (1994), pp. 255-271. https://doi.org/10.1006/jhge.1994.1020

McClocksey, Deirdre, "The poverty of Boldizzoni: resurrecting the German Historical School”, Investigaciones de historia económica, vol. 9, n. 1 (2013), pp. 2-6. https:// doi.org/10.1016/j.ihe.2012.12.002

Moore, Robert, La primera revolución europea, c. 970-1250, Crítica, Barcelona, 2003.

Moroni, Stefano, "Two different theories of two different spontaneous phenomena: orders of actions and evolution of institutions in Hayek", Cosmos and Taxis, vol. 1, n. 2 (2014), pp. 9-23.

Musset, Lucien, "Foires et marchés en Normandie à l'époque ducale", Annales de Normandie, vol.26, n.1 (1976), pp.3-23. https://doi.org/10.3406/annor.1976.5157

North, Douglass C.; Paul R. Milgrom y Barry R. Weintgast, "The role of institutions in the revival of trade: the law merchant, private judges and the Champagne fairs", Economics and Politics, vol.2, n.1 (1990), pp. 1-23. https://doi. org/10.4324/9781315082349-37

North, Douglass C. y Robert P. Thomas, El nacimiento del mundo occidental. Una nueva historia económica (900-1700), Siglo XXI, Madrid, 1978.

Ogilvie, Sheylagh, Institutions and European trade. Merchant guilds, 1000-1800, Cambridge University Press, Cambridge, 2011. https://doi.org/10.1017/ cbo9780511974410.003

Ogilvie, Sheylagh, "Whatever is, is right? Economic institutions in preindustrial Europe", Economic History Review, vol. 60, n. 4 (2007), pp. 649-685. https://doi. org/10.1111/j.1468-0289.2007.00408.x

Pirenne, Henri, Las ciudades en la Edad Media, Crítica, Barcelona, 1990.

Henri Pirenne, Historia económica y social de la Edad Media, Fondo de Cultura Económica, México D.F., 1969.

Poly, Jean-Pierre y Éric Bournazel, El cambio feudal (siglos X-XII), Editorial Labor, Barcelona, 1983.

Postan, Michael M., Essays on medieval agriculture and general problems of the medieval economy, Cambridge University Press, Cambridge, 1973.

Postan, Michael M., Medieval Trade and Finance, Cambridge University Press, Cambridge, 1973.

Pryor, John H. , "The origins of the commenda contract", Speculum, vol.52, n. 1 (1977), pp. 5-37.

Rodríguez-Picavea Matilla, Enrique, "La ganadería en la Castilla medieval: una revisión historiográfica”, Medievalismo, vol. 8 (1998), pp. 111-153.

Roover, Raymond de, "The organisation of trade", en Michael M. Postan, E.E. Rich. y Edward Miller (eds.), The Cambridge economic history of Europe from the decline of the Roman Empire. Vol.3: economic organisation and policies in the Middle Ages, Cambridge University Press, Cambridge, 1963, pp.42-118. https://doi. org/10.1017/chol9780521045063.003 
Rösener, Werner, Los campesinos en la Edad Media, Crítica, Barcelona, 1990.

Peter Spufford, Power and profit: the merchant in medieval Europe, Thames \& Hudson, London, 2002.

Stromberg, Joseph R., 'Douglass C.North and non-marxist institutional determinism', Journal of Libertarian Studies, vol.16, n.4 (2002), pp. 101-137.

Verhulst, Adrieen, The rise of cities in North-West Europe, Cambridge University Press, Cambridge, 1999.

Verlinden, Charles, "Markets and fairs", en Michael M. Postan, E.E. Rich. y Edward Miller (eds.), The Cambridge economic history of Europe from the decline of the Roman Empire. Vol.3: economic organisation and policies in the Middle Ages, Cambridge University Press, Cambridge, 1963, pp. 119-154. https://doi.org/10.1017/ chol9780521045063.004

White, Stephen D., "Debate: the "feudal revolution": II", Past\&Present, vol.152 (1996), pp. 197-205.

Wickham, Chris, Una historia nueva de la Alta Edad Media, 400-800, Crítica, Barcelona, 2009.

Wickham, Chris, 'Debate: the "feudal revolution": IV', Past\&Present, vol.155 (1997), pp. 208-223. https://doi.org/10.1093/past/155.1.196

Wickham, Chris, "La mutación feudal en Italia”, en Antonio Malpica y Tomás Quesada, Los orígenes del feudalismo en el mundo Mediterráneo, Universidad de Granada, Granada, 1994, pp. 31-57.

Witt, Ronald G., "The landlord and the economic revival of the Middle Ages in Northern Europe, 1000-1250”, American Historical Review, vol.76, n.4 ( 1971), pp. 965-988. https://doi.org/10.2307/1849238 